EXTENDED REPORT

\title{
Rituximab dissociates the tight link between disease activity and joint damage in rheumatoid arthritis patients
}

\author{
Daniel Aletaha, ${ }^{1}$ Farideh Alasti, ${ }^{1}$ Josef S Smolen ${ }^{1,2}$
}

${ }^{1}$ Division of Rheumatology, Department of Medicine 3, Medical University of Vienna, Vienna, Austria ${ }^{2}$ Division of Rheumatology, 2nd Department of Medicine, Hietzing Hospital, Vienna, Austria

\section{Correspondence to}

Professor Daniel Aletaha, Division of Rheumatology, Department of Medicine 3, Medical University of Vienna, Waehringer Guertel 18-20, Vienna A-1090, Austria; daniel.aletaha@meduniwien. ac.at

Received 7 May 2012 Accepted 20 July 2012 Published Online First 21 August 2012

\section{CPLinked}

- http://dx.doi.org/10.1136/ annrheumdis-2012-202650

\section{ABSTRACT}

Background/objective Progression of joint damage is linked to disease activity. This link is dissociated upon treatment with tumour necrosis factor (TNF)- or IL-6inhibitors plus methotrexate (MTX). It is hitherto unknown if this may also be true for therapies targeting B-cells. We thus evaluated if rituximab (RTX) therapy inhibits joint damage irrespective of its effects on disease activity. Methods We used a random $90 \%$ sample of data from two arms of the IMAGE trial comprising patients with active early rheumatoid arthritis (RA) receiving MTX $(n=188)$ or MTX + RTX $1000 \mathrm{mg}(\mathrm{n}=204)$. Patients were divided into low, moderate and high disease activity at one year of treatment by simplified disease activity index (low disease activity (LDA), moderate disease activity (MDA), high disease activity (HDA)), or by swollen joint count (SJC) or C reactive protein (CRP) tertiles. Progression of damage by the Genant modified total Sharp score (TGSS) was compared between therapies (Kruskal-Wallis, Wilcoxon tests) for each of these subgroups.

Results In patients treated with MTX, 1-year progression of TGSS In LDA, MDA and HDA was $0.40 \pm 0.88,1.04$ \pm 1.73 , and $1.31 \pm 3.02$, respectively. In contrast, on RTX + MTX, TGSS progression was $0.38 \pm 1.07,0.39 \pm 1.28$, and $-0.05 \pm 0.44$, respectively (for MDA and HDA the progression of TGSS was significantly lower in the combined group than in the MTX group: $p=0.003$ and $p=0.05$, respectively). Additional analyses (tertiles of SJC, $\mathrm{CRP}$, and matching for disease activity) confirmed the primary analysis.

Conclusions In early RA, progression of joint damage increases with increasing disease activity on MTX. RTX plus MTX retards damage independently of its effects on disease activity, since even in HDA destruction is halted, contrasting MTX monotherapy. This indicates that beyond cytokine blockade (TNF- and IL-6 inhibitors), also celldirected therapy (anti-CD20 antibody) conveys profound anti-destructive effects and dissociates the link between disease activity and joint damage.

Joint damage is an early and major characteristic of rheumatoid arthritis (RA). Observations on its natural course reveal that within 1-2 years up to $75 \%$ of the patients experience radiographic changes. ${ }^{1-4}$ The extent of these abnormalities accrues in an often linear fashion over time and is tightly related to disease activity ${ }^{2}{ }^{5-7}$. In this respect, joint swelling and acute phase reactants (APR) are the major drivers of bone and cartilage destruction; this association is also seen with composite measures of disease activity which comprise these components. ${ }^{25-8}$ Importantly, joint damage in RA is mostly irreversible and linked to irreversible disability. ${ }^{910}$

Disease modifying antirheumatic drugs (DMARDs), whether synthetic ${ }^{11} 12$ or biologic, interfere with progression of joint destruction, whereby the combination of a biologic with a synthetic DMARD conveys the strongest effects. ${ }^{13}$ Interestingly, combinations of tumour necrosis factor (TNF)-inhibitors with methotrexate (MTX) dramatically reduce and partly uncouple the above mentioned association of disease activity with destruction as assessed by radiographic measures,${ }^{14-16}$ in other words they reduce radiographic progression regardless of the disease activity level reached. This may presumably be related to a higher cytokine (TNF) level threshold for induction of joint damage than that for induction of signs and symptoms of inflammation. ${ }^{17}$ TNF-inhibition might then more rapidly and completely affect disease pathways, leading to an inhibition of both damage and inflammatory signs and symptoms, but at least gets most patients below the damage threshold, even if they continue with their clinical disease activity. A similar finding was recently made for inhibition of interleukin (IL)-6 with tocilizumab. ${ }^{18}$ Both TNF and IL-6 blockers inhibit proinflammatory cytokines which are believed to play a major role in the pathways leading to osteoclast and chondrocyte activation, the pivotal populations responsible for bony and cartilage damage. ${ }^{19} 20$ Whether this dissociation also occurs when further upstream cells or molecules are targeted is currently unknown, since respective analyses for co-stimulation blockade or B-cell depletion have not yet been performed.

In the pathogenetic cascade of RA, B-cells appear to play a prominent role. They form autoantibodies, have the capacity to present antigens, have costimulatory activity and produce a variety of cytokines; they are therefore important players in autoimmune inflammatory diseases. ${ }^{21-23}$ In addition, B-cells express receptor activator of nuclear factor $\mathrm{\kappa B}$ ligand (RANKL), ${ }^{24} 25$ the key cytokine leading to differentiation and activation of osteoclasts. ${ }^{26} 27$ Thus, the mode of action of targeting CD20 positive B-cells, as conveyed by rituximab (RTX), is presumably multifactorial: it may involve direct inhibition of damage by elimination of RANKL expressing cells; its effects may also be indirect by elimination of a cell population producing inflammatory cytokines and 
presenting antigen, but also by reduction of autoantibody production and immune complexes generation and immune complex mediated macrophage activation. ${ }^{28}$ Whether the potential effects of anti-CD20 therapy are multidimensional or involve just individual aspects, it is conceivable that RTX therapy might dissociate the link between disease activity and joint damage, just like TNF and IL- 6 blockers do. This question was the focus of the analyses presented here.

\section{PATIENTS AND METHODS}

\section{Patients}

We were kindly provided by the trial sponsor a $90 \%$ random sample of patient level data from two arms of the IMAGE trial $^{29}$ comparing the effects of MTX monotherapy with a combination of MTX plus rituximab at the licensed dose of two $1000 \mathrm{mg}$ infusions given 2 weeks apart and possible retreatment as previously specified ${ }^{29}$ on signs and symptoms as well as radiographic changes in patients with early RA who were naïve to MTX.

The data included demographic characteristics as well as clinical variables, such as swollen and tender joint counts (SJC, TJC), patient's and physician's global and patient's pain assessments, APR levels (C-reactive protein (CRP) and erythrocyte sedimentation rate (ESR)), and the health assessment questionnaire disability index (HAQ). From the respective data composite measures of disease activity, such as the Disease Activity Score using 28 joint counts (DAS28), the simplified and the clinical disease activity indices (SDAI, CDAI) were calculated according to established formulae. ${ }^{30}$ For determination of disease activity states, remission, low, moderate and high disease activity (LDA, MDA, HDA) were defined using the respective cutpoints. ${ }^{30}$ Clinical data were available between monthly and every 3 months from baseline through 2 years.

Radiographs had been assessed using the Genant modified total Sharp score (TGSS) ${ }^{31}$ by two independent readers blinded to treatment assignment, chronological order of radiographs and patients' clinical responses. This method evaluates hands and feet separately for joint space narrowing (JSN) and erosions (ERO) with a maximal total score of 200, which is about half as high as the modified Sharp score (maximal score: 398) and somewhat less than half as high as the van der Heijde modified (vdH-) Sharp score (maximal score: 448). ${ }^{32}$ Given that the increments in the TGSS are based on steps of 0.5 and $\mathrm{x}$-rays were assessed by two readers, unequivocal progression of joint damage, in line with previous considerations, ${ }^{33}$ will be regarded as an average score of $>0.25$.

For the analyses of this study, we assessed patients with complete data sets, which required the availability of clinical and radiographic data at least at baseline and 12 months; a total of 392 patients fulfilled these criteria. These patients had randomly been allocated to receive MTX plus placebo infusions $(n=188)$ or MTX plus RTX infusions at $1000 \mathrm{mg}(n=204)$ on day 0 and 14. No significant difference in demographic or clinical variables between patients who had complete datasets and those whose data were incomplete were seen (data not shown).

\section{Analyses}

Progression of radiological damage in the MTX monotherapy and RTX plus MTX treatment arms was calculated by determining the difference between the 1 year and baseline scores $(\Delta$ TGSS). The relationship between progression of joint damage and disease activity was assessed in several ways.

We first assessed patients who had attained different disease activity states by SDAI at 1 year, namely LDA or remission (SDAI $\leq 11), \mathrm{MDA}(11<\mathrm{SDAI} \leq 26)$, or HDA (SDAI >26), comparing the core set variables and progression of joint damage within these states between the two treatment groups. Since it is well established that particularly CRP levels and swollen joint counts are tightly related to progression of joint damage, ${ }^{2} 8$ we compared in an additional analysis the progression of joint damage between the treatment groups for each tertile of SJC and of CRP. In order to have the same tertile cutpoints in the placebo and in the active treatment arm, they were defined in the pooled population.

Since each of the disease activity groups (remission/LDA, MDA, or HDA) may still differ between the MTX and the

Table 1 Characteristics of patients in the MTX monotherapy arm and the RTX plus MTX arm, at baseline and after 1 year (mean \pm SD, unless indicated otherwise)

\begin{tabular}{|c|c|c|c|c|c|c|}
\hline & \multicolumn{3}{|l|}{ Baseline } & \multicolumn{3}{|l|}{1 year } \\
\hline & $P L+M T X$ & RTX + MTX & $\mathbf{p}$ & PL+MTX & RTX+MTX & $\mathbf{p}$ \\
\hline $\mathrm{N}$ & 188 & 204 & NS & 188 & 204 & NA \\
\hline Disease duration (years) & $0.9 \pm 1.0$ & $1.0 \pm 1.3$ & NS & - & - & NA \\
\hline Rheumatoid factor (\% pos.) & 88.3 & 87.3 & NS & - & - & NA \\
\hline Swollen joint count (0-28) & $13.8 \pm 6.3$ & $14.9 \pm 6.6$ & NS & $4.0 \pm 5.2$ & $2.46 \pm 3.5$ & $<0.1$ \\
\hline Evaluator global $(0-100 \mathrm{~mm})$ & $69.2 \pm 17.5$ & $68.4 \pm 17.3$ & NS & $27.0 \pm 21.8$ & $16.3 \pm 15.1$ & $<0.001$ \\
\hline Pain $(0-100 \mathrm{~mm})$ & $64.2 \pm 22.9$ & $63.5 \pm 23$ & NS & $27.7 \pm 23.3$ & $19.2 \pm 18.9$ & $<0.001$ \\
\hline C-reactive protein (mg/dl) & $3.0 \pm 2.6$ & $3.0 \pm 2.8$ & NS & $1.4 \pm 1.8$ & $0.6 \pm 1.3$ & $<0.001$ \\
\hline Erythrocyte sedimentation rate $(\mathrm{mm} / \mathrm{h})$ & $62.0 \pm 28.2$ & $58.7 \pm 31.3$ & NS & $38.9 \pm 26.1$ & $24.0 \pm 17.7$ & $<0.001$ \\
\hline Disease Activity score 28 & $7.1 \pm 1.0$ & $7.1 \pm 1.0$ & NS & $4.4 \pm 1.6$ & $3.5 \pm 1.4$ & $<0.001$ \\
\hline Change in TGSS & - & - & NA & $0.81 \pm 1.9$ & $0.35 \pm 1.1$ & $<0.001$ \\
\hline
\end{tabular}

MTX, methotrexate; NS, not significant ( $\mathrm{p} \geq 0.05$ ); NA, not applicable; RTX, rituximab; PL, placebo; TGSS, Genant modified total Sharp score. 
MTX+RTX groups regarding their average numerical level of disease activity, we investigated the subgroups for differences in disease activity between the two treatment arms. We then matched patients of the two treatment arms according to the variables that showed differences, and compared the radiographic progression between the matched MTX+placebo and MTX+RTX patients.

\section{Statistical analyses}

For assessments of differences within each of the treatment group, the Kruskal-Wallis test was used. For comparisons between treatment groups, Wilcoxon test was employed. All analyses were performed using SAS V.9 (SAS, Cary, Illinois, USA).

\section{RESULTS}

General outcomes in the MTX and RTX+MTX populations

Table 1 depicts the baseline and 1 year characteristics of the patients assessed in this study. Overall, both baseline demographic data and values of individual variables and composite measures of disease activity were similar among the groups, with slight numerical variations as seen in other studies. Likewise, impairment of physical function, as assessed by the $\mathrm{HAQ}$, and TGSS as well as ERO and JSN scores were very similar. At 1 year, however, in line with the data from the original publication, ${ }^{29}$ there was a significant difference between the two groups in essentially all endpoints, including progression of joint damage (table 1). Of note, and an important aspect for this study, the change of the TGSS was very small even in the MTX treated population due to the relatively low range of the score employed and the more recently observed trend toward less progression of joint damage in recent years. ${ }^{30} 323435$ Consequently, the overall signal for the radiographic analyses, which is the focus of this study, is small.

Radiographic changes in the two treatment groups in relation to disease activity levels

As depicted in figure 1A, there was a steady increase in joint damage with increasing disease activity state at 1 year in patients treated with MTX which almost reached statistical significance (mean \pm SD: $0.40 \pm 0.88,1.04 \pm 1.73$ and $1.31 \pm 3.02$, respectively; $p=0.058$ ). This clearly confirms previous notions that increasing disease activity leads to increasing progression of destruction, but also that even on a non-biologic DMARD like MTX, attainment of a good clinical outcome will inhibit progression of joint damage. ${ }^{16}$

In contrast, treatment with RTX plus MTX inhibited joint damage progression across all disease activity states to a similar degree $\quad(0.38 \pm 1.07, \quad 0.39 \pm 1.28, \quad-0.05 \pm 0.44, \quad$ respectively; $\mathrm{p}=0.5$ ). While in $\mathrm{LDA} /$ remission RTX + MTX did not convey added benefit beyond the result attained with MTX alone (difference in scores 0.02), we found remarkable differences comparing the average progression between the two treatment groups in the higher disease activity states, namely 0.65 in $\mathrm{MDA}$ and 1.36 in HDA ( $p=0.003$ and $p=0.05$, respectively). In figure $1 \mathrm{~B}$ and $\mathrm{C}$ the respective changes of the ERO and JSN scores are shown, revealing that the effects essentially involved both components of the TGSS. It is noteworthy that in MDA and HDA, where the large differences in radiographic scores between MTX and RTX+MTX were seen, joint counts were similar among the treatment groups, but APR were lower upon RTX+MTX therapy compared with MTX alone (table 2).
Radiographic changes in the two treatment groups in relation to joint swelling or CRP levels

When we evaluated radiographic outcomes for the two therapies within tertiles of SJC, patients treated with MTX monotherapy had the highest progression of joint damage if they were in the highest SJC tertile at 1 year (x-ray progression from highest to lowest tertile: $1.33 \pm 2.7,0.67 \pm 1.15$ and $0.32 \pm 0.68$, respectively, $\mathrm{p}=0.009$, Kruskal-Wallis; figure 2A). In contrast, upon RTX + MTX therapy, even in the highest SJC tertile at 1 year, there was only little progression $(0.31 \pm 0.82,0.46 \pm 1.5$ and $0.28 \pm 0.88$, respectively, $p=0.97$ ), and the increase with increasing activity category was also abrogated. The biggest difference to the monotherapy group was seen in the highest tertile $(p=0.034)$.

Similar observations were made when tertiles according to 1 year CRP values were assessed (figure $2 \mathrm{~B}$ ); respective data for MTX monotherapy were $1.18 \pm 2.49,0.48 \pm 0.93$, and $0.46 \pm 0.86$

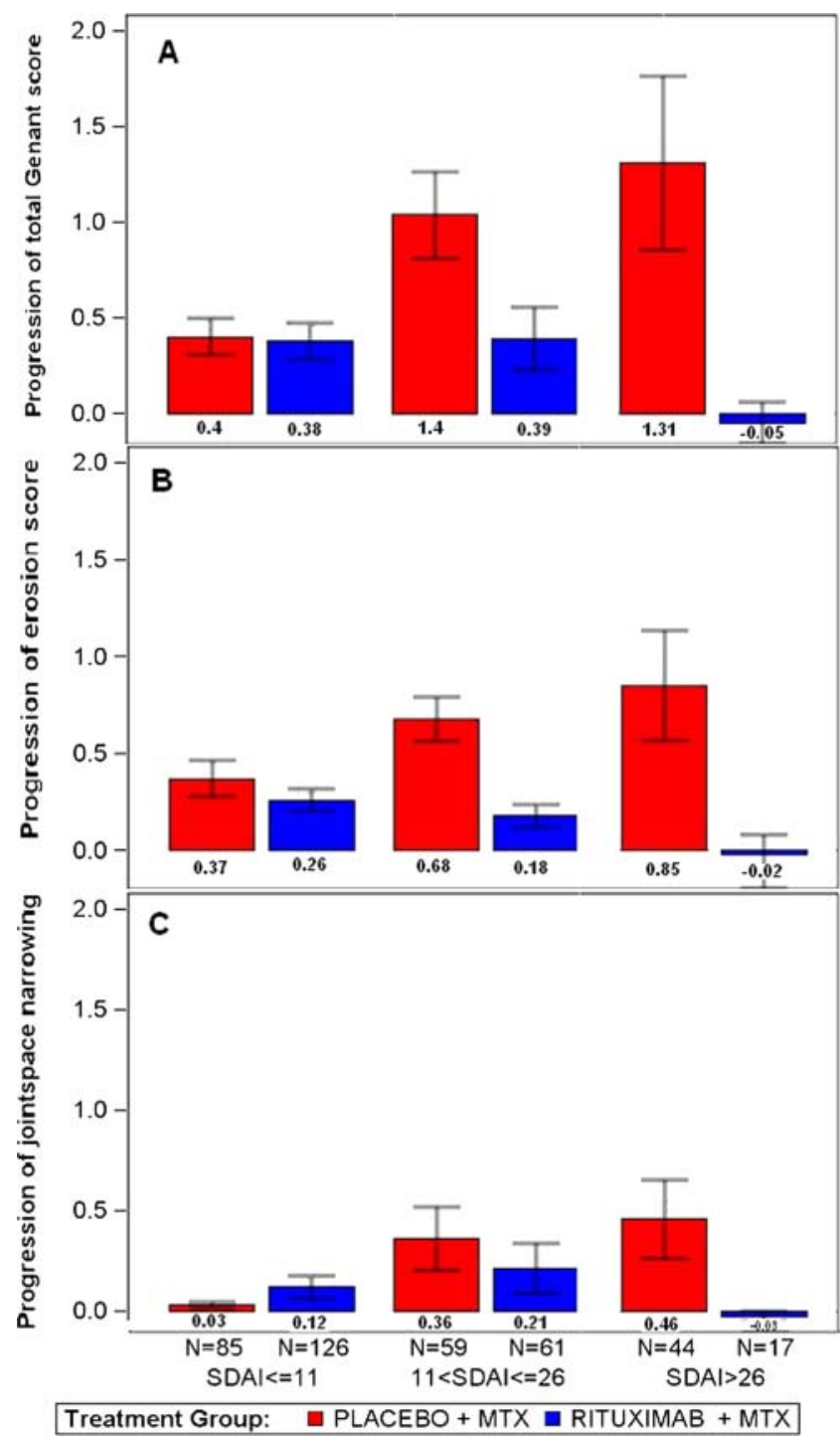

Figure 1 One year progression of joint damage by Genant modified total Sharp Score (TGSS) (means \pm SE) in patients treated with methotrexate (MTX) (red bars) or rituximab+MTX (blue bars) and divided according to disease activity states (low disease activity, moderate disease activity, HAD) as attained at 1 year of treatment. (A) Progression of TGSS. (B) Progression of the erosion score. (C) progression of the joint space narrowing score. This figure is only reproduced in colour in the online version. 
Table 2 Characteristics of patients in the MTX monotherapy arm (PL+MTX) and the RTX plus MTX combination arm (RTX+MTX) at 1 year according to their 1 year disease activity state (mean \pm SD)

\begin{tabular}{|c|c|c|c|c|c|c|c|c|c|}
\hline & \multicolumn{3}{|l|}{ SDAI $\leq 11$} & \multicolumn{3}{|c|}{$11<$ SDAI $\leq 26$} & \multicolumn{3}{|l|}{ SDAI $>26$} \\
\hline & PL+MTX & RTX+MTX & $\mathbf{p}$ & PL+MTX & RTX+MTX & $\mathbf{p}$ & PL+MTX & RTX+MTX & $\mathbf{p}$ \\
\hline $\mathrm{N}$ & 85 & 126 & NA & 59 & 61 & NA & 44 & 17 & NA \\
\hline Tender joint count $(0-28)$ & $1.5 \pm 1.7$ & $0.9 \pm 1.3$ & $<0.01$ & $5.9 \pm 3.4$ & $7.4 \pm 3.6$ & $<0.05$ & $16.0 \pm 5.7$ & $17.9 \pm 7.5$ & NS \\
\hline Patient global $(0-100 \mathrm{~mm})$ & $13.9 \pm 13.7$ & $12.6 \pm 13.3$ & NS & $38.9 \pm 21.8$ & $30.3 \pm 21.2$ & $<0.05$ & $52.6 \pm 21.4$ & $55.4 \pm 21.5$ & NS \\
\hline Evaluator global $(0-100 \mathrm{~mm})$ & $10.9 \pm 9.1$ & $8.0 \pm 7.7$ & $<0.05$ & $31.4 \pm 15.5$ & $27.1 \pm 14.3$ & NS & $52.0 \pm 19.9$ & $38.4 \pm 13.0$ & $<0.05$ \\
\hline Erythrocyte sedimentation rate $(\mathrm{mm} / \mathrm{h})$ & $29.9 \pm 20.6$ & $22.8 \pm 16.6$ & NS & $45.1 \pm 28.1$ & $27.7 \pm 20.0$ & $<0.001$ & $48.1 \pm 27.8$ & $20.0 \pm 15.5$ & $<0.001$ \\
\hline Disease Activity score 28 & $3.0 \pm 0.8$ & $2.7 \pm 0.8$ & $<0.001$ & $4.8 \pm 0.7$ & $4.5 \pm 0.8$ & NS & $6.4 \pm 0.8$ & $5.7 \pm 1.0$ & $<0.05$ \\
\hline SDAI & $5.6 \pm 3.2$ & $4.3 \pm 2.9$ & $<0.01$ & $18.3 \pm 4.5$ & $18.0 \pm 4.0$ & NS & $39.4 \pm 11.4$ & $36.8 \pm 11.0$ & NS \\
\hline Clinical Disease Activity Index & $4.8 \pm 3$ & $3.9 \pm 2.9$ & $<0.05$ & $16.5 \pm 4.5$ & $17.3 \pm 3.9$ & NS & $37.6 \pm 10.8$ & $35.1 \pm 12.1$ & NS \\
\hline Health Assessment Questionnaire & $0.6 \pm 0.6$ & $0.5 \pm 0.5$ & NS & $1.0 \pm 0.6$ & $0.8 \pm 0.6$ & NS & $1.54 \pm 0.7$ & $1.4 \pm 0.5$ & NS \\
\hline
\end{tabular}

MTX, methotrexate; NS, not significant ( $\mathrm{p} \geq 0.05$ ); NA, not applicable; RTX, rituximab; PL, placebo; SDAl, simplified disease activity index; TGSS, Genant modified total Sharp score.

$(p=0.03)$, whereas these values for the RTX+MTX therapy were $0.23 \pm 1.06,0.44 \pm 1.42$ and $0.33 \pm 0.79 \quad(p=0.6)$, again showing the biggest difference between the treatment groups at the highest CRP activity $(p=0.0003)$.
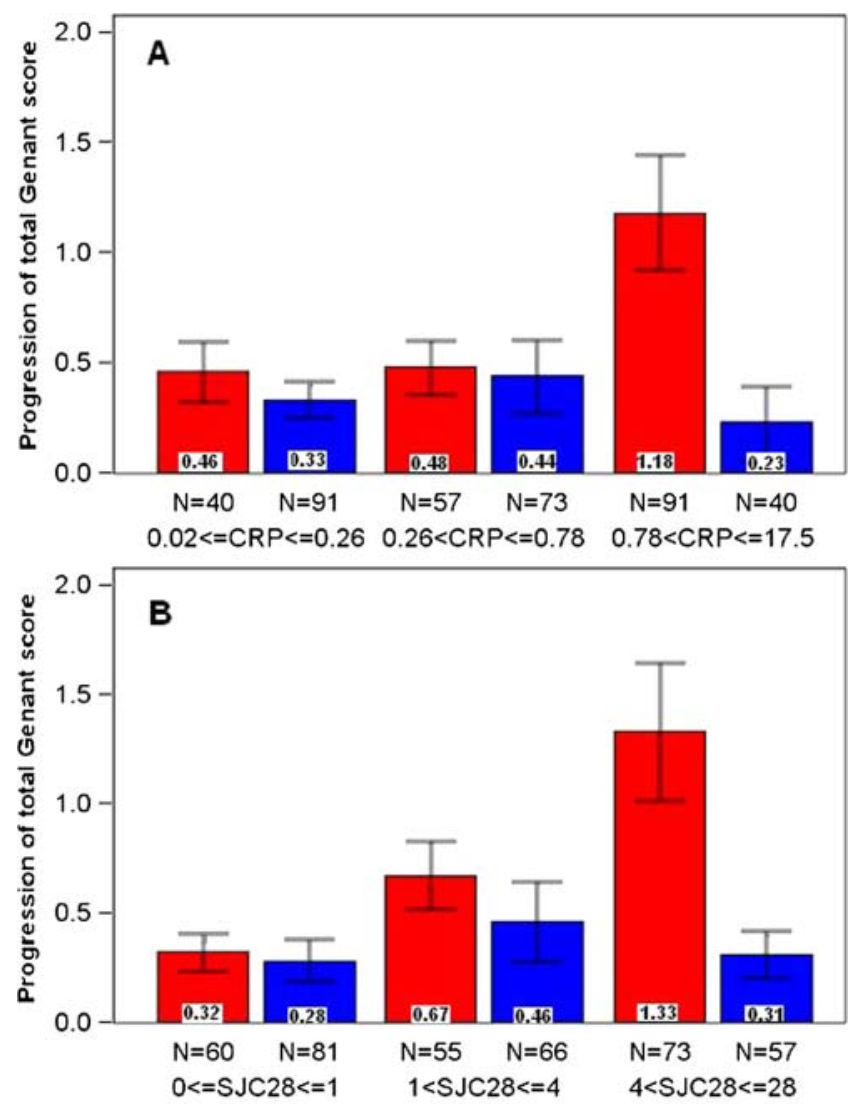

Treatment Group: $\quad$ - PLACEBO + MTX @ RITUXIMAB + MTX

Figure 2 One year progression of joint damage by Genant modified total Sharp Score (TGSS) (means \pm SE) in patients treated with methotrexate (MTX) (red bars) or rituximab + MTX (blue bars) and divided according to (A) Tertiles by swollen joint counts at 1 year and (B) tertiles by C-reactive protein at 1 year. This figure is only reproduced in colour in the online version.
Radiographic changes in exactly matched disease activity pairs from the two treatment groups

When assessing residual disease activity at 1 year among patients classified into CRP tertiles, the difference in residual CRP in the highest tertile was still significant between the treatment groups $(2.5 \pm 2.1$ for the MTX versus $1.8 \pm 2.6$ for the RTX+MTX groups, $p=0.003)$, and also ESR and CDAI were lower (not shown). Therefore, in a final analysis, we matched the patient populations for CRP, ESR and CDAI at 1 year and found 52 patients in each treatment group in whom these variables and also swollen and tender joints were similar. Despite successful matching for disease activity, the MTX monotherapy cohort progressed significantly more than the RTX+MTX group $(0.9 \pm 1.5$ vs $0.3 \pm 1.4, p<0.007$, Kruskal-Wallis test).

\section{DISCUSSION}

Cytokine inhibition with biological agents directed at TNF or IL-6 has been previously shown to dissociate the usual tight link between disease activity and progression of joint damage in all populations studied, early or late, and with all TNF-blockers that were assessed in this respect. ${ }^{14} 1536$ Indeed, in the present study the link between disease activity and progression of joint damage has again been observed in the control group of patients, in whom it occurred despite newly introduced treatment with MTX. However, our study revealed that therapy with RTX in combination with MTX disassociates this link. Thus, this finding is now expanded from effects previously assumed to be primarily, if not exclusively, related to direct cytokine inhibition to B-cell-directed therapy. This finding was consistent across several types of analyses, including patients matched for disease activity at the 1 year time point. The data show that among patients who attain low disease activity or remission by composite measures, CRP or swollen joint counts, progression of joint damage is minimised whether treated with MTX or RTX plus MTX. In contrast, at higher states of disease activity, patients treated with MTX experienced significant increases in damage progression, whereas this was dramatically inhibited among those receiving RTX plus MTX. This finding pertained to both ERO and JSN. The fact that the radiographic changes in the RTX group with high disease activity were even smaller than in the low moderate or low disease activity 
groups, can be considered a mere play of chance, particularly as the number of patients in this group is small.

While we do not exactly know the mechanism of action for any of these findings, be they related to cytokine inhibition or B-cell depletion, the amplifying role of TNF and IL-6 on osteoclasts suggested that their inhibition may more directly relieve the load that is conveyed by these cytokines on joint damage. How could B-cell depletion act in this regard? It could deliver this effect by reducing autoantibody levels and thus immune complex formation; immune complexes which are present in the RA cartilage, synovium, and synovial fluid, ${ }^{37-40}$ can bind to Fc, complement and/or Toll-like receptors on macrophages and thus induce proinflammatory cytokine production. ${ }^{40-42}$ This can lead to cartilage and bone damage via the effects of these cytokines on chondrocytes and osteoclastogenesis, but also by direct action on osteoclastogenesis via activation of spleen tyrosine kinase (Syk), an important signal transduction pathway downstream of Fc receptors that also influences differentiation of osteoclasts. ${ }^{43}$ Decrease in autoantibody production via B-lymphocyte depletion may thus reduce the activation of cells involved in inflammation and destruction by decreasing circulating as well as local immune complex generation. Though this assumption is speculative, it may explain the findings presented in this study and generates a hypothesis that can be prospectively tested in future studies of RTX or B-cell targeted therapy in experimental models of arthritis. Importantly, also other mechanisms of action are potentially operative, such as reduction in cytokine load due to reduction of cytokine producing B-cells, depletion of RANKL expressing B-cells or reduction of antigen presenting cells and thus interference with T-cell activation and its downstream effects.

The limitations of this exploratory analysis relate to the insufficient understanding of the mechanisms behind this observation, but also to the retrospective nature of our analysis; however, the data were prospectively collected. Interestingly, similar data were obtained across all analyses performed in spite of the low rate of progression of joint damage in this study, and they were reproduced for both, ERO and JSN, in a similar way; moreover, when assessing the radiographic progression during year 2 of the trial, similar results were obtained (not shown). The fact that we studied only MTX-naïve patients with early RA is a further limitation of our investigation. However, the IMAGE trial employed an optimal control population, namely newly started MTX treatment rather than placebo with background MTX as is usually the case in studies of established RA. Previous investigations on TNF blockers, however, had revealed that this treatment dissociates the relationship between the degree of disease activity and joint damage irrespective of the population studied, early or longstanding RA.7 141544 Similar results were obtained with tocilizumab in established RA. ${ }^{18}$ Therefore it can be assumed that the observations reported here for RTX also pertain to patients with established RA, although full clarity will require separate analyses of that population.

In conclusion, targeting CD20 positive B-cells, like inhibition of cytokines, halts progression of joint damage even in the presence of significant inflammatory disease activity. This finding further supports and expands notions that anti-CD20 therapy is a highly effective treatment modality in RA.

Acknowledgements We thank Roche for providing us with the data and a grant to perform the analyses. The study was partly supported through Coordination Theme 1 (Health) of the European Community's FP7; Grant Agreement number HEALTH-F2-2008-223404 (Masterswitch). This is a publication from the Joint and Bone Center of the Medical University of Vienna.
Contributors DA: study design, data analysis, interpretation, writing of manuscript. FA: data analysis. JSS: data acquisition, study design, data analysis, interpretation, writing of manuscript.

Competing interests DA provides expert advice and is a speaker for Roche. JSS received grant/research support, provides expert advice and is a speaker for Roche.

Ethics approval Secondary data analysis; approval for data analysis given at enrolment of the original study.

Provenance and peer review Not commissioned; externally peer reviewed.

\section{REFERENCES}

1. Plant MJ, Jones PW, Saklatvala J, et al. Patterns of radiological progression in rheumatoid arthritis: results of an 8 year prospective study. J Rheumatol 1998;25:417-26.

2. Van der Heijde DM, van Riel PL, van Leeuwen MA, et al. Prognostic factors for radiographic damage and physical disability in early rheumatoid arthritis. A prospective follow-up study of 147 patients. Br J Rheumatol 1992;31:519-25.

3. Hulsmans HM, Jacobs JW, Van der Heijde DM, et al. The course of radiologic damage during the first six years of rheumatoid arthritis. Arthritis Rheum 2000;43:1927-40.

4. Wolfe F, Sharp JT. Radiographic outcome of recent-onset rheumatoid arthritis: a 19-year study of radiographic progression. Arthritis Rheum 1998;41:1571-82.

5. van Leeuwen MA, van Rijswijk MH, Sluiter WJ, et al. Individual relationship between progression of radiological damage and the acute phase response in early rheumatoid arthritis. Towards development of a decision support system. J Rheumatol 1997;24:20-7.

6. Aletaha D, Nell VPK, Stamm T, et al. Acute phase reactants add little to composite disease activity indices for rheumatoid arthritis: validation of a clinical activity score. Arthritis Res 2005;7:R796-806

7. Smolen JS, van der Heijde DMFM, St.Clair EW, et al. Predictors of joint damage in patients with early rheumatoid arthritis treated with high-dose methotrexate without or with concomitant infliximab. Results from the ASPIRE trial. Arthritis Rheum 2006;54:702-10.

8. Aletaha D, Alasti F, Smolen JS. Rheumatoid arthritis near remission: clinical rather than laboratory inflammation is associated with radiographic progression. Ann Rheum Dis 2011.

9. Aletaha D, Smolen J, Ward MM. Measuring function in rheumatoid arthritis: identifying reversible and irreversible components. Arthritis Rheum 2006;54:2784-92.

10. Smolen JS, Aletaha D, Grisar JC, et al. Estimation of a numerical value for joint damage-related physical disability in rheumatoid arthritis clinical trials. Ann Rheum Dis 2010;69:1058-64.

11. van der Heijde DM, van Riel PL, Nuver-Zwart, et al. Effects of hydroxychloroquine and sulphasalazine on progression of joint damage in rheumatoid arthritis. Lancet 1989;1:1036-8.

12. Smolen JS, Kalden JR, Scott DL, et al. Efficacy and safety of leflunomide compared with placebo and sulphasalazine in active rheumatoid arthritis: a double-blind, randomised, multicentre trial. Lancet 1999;353:259-66.

13. Keystone E. Recent concepts in the inhibition of radiographic progression with biologics. Curr Opin Rheumatol 2009;21:231-7.

14. Smolen JS, Han C, Bala M, et al. Evidence of Radiographic Benefit of Infliximab Plus Methotrexate in Rheumatoid Arthritis Patients Who Had No Clinical Improvement: A Detailed Subanalysis of the ATTRACT Trial. Arthritis Rheum 2005; 52:1020-30.

15. Landewe R, van der Heijde D, Klareskog $L$, et al. Disconnect between inflammation and joint destruction after treatment with etanercept plus methotrexate: results from the trial of etanercept and methotrexate with radiographic and patient outcomes. Arthritis Rheum 2006;54:3119-25.

16. Smolen JS, Han C, Van der Heijde DM, et al. Radiographic changes in rheumatoid arthritis patients attaining different disease activity states with methotrexate monotherapy and infliximab plus methotrexate: the impacts of remission and TNF-blockade. Ann Rheum Dis 2009;68:823-7.

17. Smolen JS, Aletaha D, Grisar J, et al. The need for prognosticators in rheumatoid arthritis. Biological and clinical markers - where are we now? Arthritis Res Ther 2008;10:208.

18. Smolen JS, Avila JC, Aletaha D. Tocilizumab inhibits progression of joint damage in rheumatoid arthritis irrespective of its anti-inflammatory effects: disassociation of the link between inflammation and destruction. Ann Rheum Dis 2012;71:687-93.

19. Gravallese EM, Harada Y, Wang JT, et al. Identification of cell types responsiblefor bone resorption in rheumatoid arthritis and juvenile rheumatoid arthritis. Am J Pathol 1998;152:943-51.

20. Firestein GS. Evolving concepts of rheumatoid arthritis. Nature 2003;423:361. Ref Type: Journal (Full)

21. Rodriguez-Pinto D. B cells as antigen presenting cells. Cell Immunol 2005;238:67-75

22. Dorner T, Burmester GR. The role of B cells in rheumatoid arthritis: mechanisms and therapeutic targets. Curr Opin Rheumatol 2003;15:246-52. 
23. Lund FE. Cytokine-producing B lymphocytes-key regulators of immunity. Curr Opin Immunol 2008;20:332-8.

24. Choi Y, Woo KM, Ko SH, et al. Osteoclastogenesis is enhanced by activated B cells but suppressed by activated CD8(+) T cells. Eur J Immunol 2001;31:2179-88.

25. Yeo $\mathbf{L}$, Toellner KM, Salmon $\mathbf{M}$, et al. Cytokine mRNA profiling identifies B cells as a major source of RANKL in rheumatoid arthritis. Ann Rheum Dis 2011;70:2022-28.

26. Yasuda H, Shima N, Nakagawa N, et al. Osteoclast differentiation factor is a ligand for osteoprotegerin/osteoclastogenesis-inhibitory factor and is identical to TRANCE/ RANKL. Proc Natl Acad Sci USA 1998;95:3597-602.

27. Teitelbaum SL. Bone resorption by osteoclasts. Science 2000;289:1504-8.

28. Buch MH, Smolen JS, Betteridge N, et al. Updated consensus statement on the use of rituximab in patients with rheumatoid arthritis. Ann Rheum Dis 2011;70:909-20.

29. Tak PP, Rigby WF, Rubbert-Roth A, et al. Inhibition of joint damage and improved clinical outcomes with rituximab plus methotrexate in early active rheumatoid arthritis: the IMAGE trial. Ann Rheum Dis 2011;70:39-46.

30. Aletaha D, Smolen JS. The Definition and Measurement of Disease Modification in Inflammatory Rheumatic Diseases. Rheum Dis Clin North Am 2006;32:9-44.

31. Genant HK, Jiang Y, Peterfy C, et al. Assessment of rheumatoid arthritis using a modified scoring method on digitized and original radiographs. Arthritis Rheum 1998;41:1583-90.

32. van der Heijde D. How to read radiographs according to the Sharp/van der Heijde method. J Rheumatol 1999;26:743-5.

33. van der Heijde D, Simon L, Smolen J, et al. How to report radiographic data in randomized clinical trials in rheumatoid arthritis: guidelines from a roundtable discussion. Arthritis Rheum 2002;47:215-18.

34. Genant HK. Methods of assessing radiographic change in rheumatoid arthritis. Am J Med 1983;75:35-47.
35. Rahman MU, Buchanan J, Doyle MK, et al. Changes in patient characteristics in anti-tumour necrosis factor clinical trials for rheumatoid arthritis: results of an analysis of the literature over the past 16 years. Ann Rheum Dis 2011;70:1631-40.

36. Smolen JS, Martinez-Avila JC, Aletaha D. Tocilizumab inhibits progression of joint damage in rheumatoid arthritis irrespective of its anti-inflammatory effects: disassociation of the link between inflammation and destruction. Ann Rheum Dis 2012:71:687-93

37. Zvaifler NJ. Rheumatoid synovitis. An extravascular immune complex disease. Arthritis Rheum 1974;17:297-305.

38. Vetto AA, Mannik M, Zatarain-Rios E, et al. Immune deposits in articular cartilage of patients with rheumatoid arthritis have a granular pattern not seen in osteoarthritis. Rheumatol Int 1990:10:13-19.

39. Jasin HE. Autoantibody specificities of immune complexes sequestered in articular cartilage of patients with rheumatoid arthritis and osteoarthritis. Arthritis Rheum 1985;28:241-8

40. Sokolove J, Zhao X, Chandra PE, et al. Immune complexes containing citrullinated fibrinogen costimulate macrophages via Toll-like receptor 4 and Fcgamma receptor. Arthritis Rheum 2011;63:53-62.

41. Debets JM, Van der Linden CJ, Dieteren IE, et al. Fc-receptor cross-linking induces rapid secretion of tumor necrosis factor (cachectin) by human peripheral blood monocytes. J Immunol 1988;141:1197-201.

42. Aringer $\mathbf{M}$, Smolen JS. Therapeutic blockade of TNF in patients with SLE-Promising or crazy? Autoimmun Rev 2012;11:321-5.

43. Redlich K, Smolen JS. Inflammatory bone loss: pathogenesis and therapeutic intervention. Nat Rev Drug Discov 2012:11:234-50.

44. Emery P, Genovese MC, van VR, et al. Less radiographic progression with adalimumab plus methotrexate versus methotrexate monotherapy across the spectrum of clinical response in early rheumatoid arthritis. J Rheumatol 2009;36:1429-41. 